\title{
The Cultivation of Regional Innovative Culture is an Important Link to Enhance the Regional Soft Power
}

\author{
Haitao Wang \\ Department of Economics, School of Humanities and \\ Law \\ Northeastern University, N.E.U \\ Shenyang, China \\ neuwanght@163.com
}

\author{
Yaowen Chen \\ Department of Economics, School of Humanities and \\ Law \\ Northeastern University, N.E.U \\ Shenyang, China \\ cyw.neu@gmail.com
}

\begin{abstract}
A subject that how to improve the soft power of a region is discussed in this paper, and it is concerned in both theory and practice area. Through the analysis of the relationship between regional innovation culture and regional soft power, we found cultivating regional innovation culture is a key link in the process of enhancing regional soft power, and several jobs needs to be focused on in cultivating regional innovation culture are put forward.
\end{abstract}

Keyword: Region; innovation culture; soft power; competition

\section{INTRODUCTION}

Culture of innovation is an important part of a country's or a region's soft power, China's soft power in a short board. China to build an innovative country must pay attention to the cultivation of a culture of innovation.

Accompanied by the steadily improving market of China's economy system, the competitions among the Chinese regions have been an important driving force of China's transformation of economic development, of sustainable economic development and of raising their levels. From the basic situation of competition among China's regional competition is mainly concentrated in the central dispute policy, competing with other regional technology to fight for the project to fight for investment. To the central competition policy is to obtain a pilot basis in some areas and to the central special attention in terms of policy. Compete with other regions, to compete the project; investment dispute is to gather the resources to create conditions for the development of regional extraordinary. Technology, striving for regional projects and investment in basic basically comes from outside the region, relying on the special preferential policies provided by the region. However, due to excessive competition among regions in the competition for resources has led to the region between the duplicated construction, industrial structures, the expense of the economies of scale, the expense of the effect of the specialized division of labor and many other issues. While this competitive situation remains will continue, but the competition's focus on the intrinsic strength of the regional economic development, will become another important feature of competition between future regional. The strength of regional innovation capability is the inherent strength of the regional economic development performance. The important support of the regional culture of innovation as a regional soft power, its culture of innovation is good or bad is the important factor is the formation of regional innovation capability and how to cultivate a regional culture of innovation has become a key link to cultivate regional soft power.

\section{REGIONAL INNOVATION CULTURE IS AN IMPORTANT SUPPORT OF REGIONAL SOFT POWER}

In accordance with the understanding of Joseph Nye's "soft power" refers to the elements of the external attractiveness of the main actors of the international political body (e.g. national) culture, values, national spirit, lifestyle, image, system mode, affinity, appeal power and influence. If we will be summarized based on Joseph Nye, soft power understand the external attractiveness of a country or region culture, then, in the culture of a country or region included in the continued healthy development and enhance the competitiveness of a country or region lasting play a role in the force can be called the force of a country's culture and internal support. External attraction and internal support for a national or regional culture, mutual promotion and mutual restraint, together constitute a complete system of the soft power of the country or region.

Internal support for the soft power of the country or region should include the cultural elements of national cohesion, coordination and innovative. In traditional Chinese culture, innovation in our internal support force which is a relatively weak force. The main reason for the weak innovation is the factor of China's traditional culture, a culture of innovation is relatively lacking.

Innovation is creating new knowledge, new ideas, new technologies, new patents, new products, the sum of the thinking and behavior. The so-called culture of innovation is especially the cultural patterns related to the practice of innovation, independent innovation, the core is to stimulate innovation, encourage exploration, inclusive personality, tolerance of failure. Also scholar's culture of innovation specific broad as the main culture of innovation, institutional culture of innovation and environmental innovation culture connotation of the three levels of. The main culture of innovation is the main body of innovation people necessary cultural characteristics (such as the sum of the spirit, thought, knowledge, values, ways of thinking, psychological quality, ethics, behavior, etc.) and its 
innovative activities with cultural factors; institutional culture of innovation contribute to the sum of the cultural factors in the innovation activities of institutions, mechanisms, policies; environmental innovation culture is contained in a variety of social environment conducive to innovation activities, atmosphere, service platform the sum of the cultural factors. A country has an overall national innovation culture of a country belong to different regions (China mainly for the different administrative region) there are different regions of the culture of innovation. Regional culture of innovation is in line with the values of the regional innovation system, mode of thinking, rules of conduct, institutional system, the sum of the spiritual atmosphere. In the pattern of the future inter-regional competition, innovation and cultural differences will inevitably lead to differences in innovative ability, and performance differences of the different regions of soft power, soft power differences inevitably lead to the differentiation of the overall strength, the ultimate impact of the Chinese regional economic development strategy successfully implemented.

Building the innovative country, Chinese government deal with the challenge of the world situation profound changes in the new stage of the new century made a major strategic decision. The scholar thinks, realize the goal of building the innovative country, besides need certain material guarantee beyond, the key is to cultivate, development and prosperity of culture of innovation for the innovation-type national construction build a relaxed and harmonious, healthy and positive culture atmosphere, for innovation activities to build a advocating innovation, tolerance failures, support and encourage the eminence adventure culture platform, thus to the building of an innovation-oriented country determines the innovation era, lay the solid foundation. Because the innovative culture is an important prerequisite for boost innovation and constructing innovative country core resources, is raising the national innovation ability and the competitiveness of important foundation, to provide the innovation-type national construction ideological basis, power support and the system guarantee.

China's actual situation in various areas of national strategic guidance to build an innovative country, has already begun from multiple aspects concern the construction of the regional innovation system, regional innovation capacity started to pay attention to a related resource aggregation effect. But generally speaking, to cultivate a culture of innovation to enhance the innovative capacity is not an overnight thing, you need a long historical process, while the behavior of orientation of the local government is often short-term, therefore, how to cultivate a culture of innovation does not really become Government focus of the study. However, in order to fundamentally improve the innovative capacity of a region, ultimately to enhance the innovation capability of China as a whole must have long-term planning. Which regional policy makers as soon as possible to establish a strategic awareness, as soon as possible to start from a little bit of the cultivation of a culture of innovation, which area will be in the regional competition in the future due to the innovation capacity appeared certain to win, otherwise, it is only in a passive situation.

\section{FOCUS ON SEVERAL IMPORTANCE OF THE PROCESS OF REGIONAL CULTURE INNOVATION}

Culture of innovation, as informal constraints that regulate the sexual behavior standards, the formation and perfection need to go through a long process. Clear culture of innovation for the region have realized that to cultivate a culture of innovation importance in terms of, you must cultivate is not easy, but to the cultivation of a culture of innovation as a systems engineering task. To cultivate a regional culture of innovation, not only from the cultural value system construction to start, but also in terms of system design to build a good atmosphere and environment for innovation. Region to cultivate a culture of innovation, need to tap the creative elements that are already in the local culture on the one hand, on the other hand, the need to introduce innovative elements contained in the foreign and domestic innovation capability District Cultural and innovative elements in the culture of the region be integrated to form a more competitive, the soft power of the region of the supporting force of the culture of innovation. Specifically, the various provinces and autonomous regions of China, the actual departure from the regional development to foster a culture of innovation, you need to focus on the following work.

First of all, through the flexible method, improve the regional innovative cultivation of social recognition of the importance of culture. According to a specific administrative region, if had been will cultivate the innovative culture as promote the region of the soft power of the strategic measures, in its economic and social development program will be the implantation of innovative culture as a long-term strategic task, and will the implantation of innovative culture through to the every policy of link; In the provinces of the main media in continuous related innovation culture subject, let the people from the level of ideas advocated by the government really aware of the innovation of regional culture and people's production and life development importance; In elementary school, junior high school, high school and university education link, strengthen creative thinking, systematic thinking and risk spirit training, encourages independent thinking, encourage put a different point of view, being "dare to encourage behavior; Mining, synthesized and summarized the successful experience of innovation, in fact prove innovation behavior to produce and the innovation of the innovation behavior culture of the economic development and social progress of significance.

Secondly, Attract and develop quality and innovative technology professionals, the Firm Foundation for the cultivation of the regional culture of innovation. A regional culture of innovation development and implementation of innovative behavior depends largely on the amount of the innovative talent in the region. Innovative human resources of a regional innovation activities, the probability of success of the innovative behavior is bound to form a focus on 
innovation in a regional context, innovation, and support innovation and actively participate in a good atmosphere of innovation. A regional innovation talent is nothing more than from two aspects, namely culture within the region and from outside the region to attract. Education system and talent growth environment in the region should be adjusted in accordance with the law of growth of innovative talent in order to facilitate a native of innovative talents continue to stand out. Outside the region (including foreign) innovation attracting foreign talent, depends critically on the implementation of regional innovation behavior to create a suitable environment, appropriate to the environment of the implementation of innovative behavior, not only to continue to attract innovative talents from outside the region, natural can also serve to retain the effectiveness of local creative talent in the local implementation of innovative behavior.

Thirdly, give full play to the government's leading role; build on implementing innovation behavior of social environment. Because innovation behavior of great uncertainty, once the success of great interest of spillovers. If the corresponding risk entirely by the main body of the implementation of the innovation behavior to undertake, the economic development and social progress in urgent need of innovation behavior will seriously insufficient. For this reason, the government must play in which a help innovation subject risks and for innovation subject bold implementation innovation behavior to escort role. The government of the special role, main performance for all kinds of innovation in of the main body of the innovation behavior to provide all kinds of public services; To strengthen the government to technological innovation goes straight, optimize the allocation of resources of science and technology; Constantly perfect the legal system environment, intensify protection of intellectual property, protect the rights of the independent innovation subject; The implementation of incentive the independent innovation of tax policy and support the financial policies of the independent innovation, arouse the enthusiasm of the main body of independent innovation, etc.

Fourthly, strengthen the construction of enterprise culture of innovation, to stimulate the vitality of enterprises' technological innovation. Increasingly perfect socialist market economic system in China, competition in the market of micro-economic entities, but also in technological innovation. To build a regional culture of innovation, enterprise is the main force. In the highly competitive market, enterprises there is no lack of sense of crisis, but how the crisis as an opportunity, it is the problem of troubled enterprises. Gene to cultivate a culture of innovation in the enterprise, companies really know how the constant innovation in order to allow enterprises and remain invincible in the competition. With the vitality of enterprises to innovate continue to be inspired by, the competitiveness of enterprises has been improved, advocating innovation in the enterprise, an active part in the innovative gene will be strengthened. The successful experience of the typical innovative enterprises should conscientiously sum up and make it play a leading role in the construction of the regional culture of innovation and thus the diffusion and penetration of the culture of innovation in regional economic development. Accompanied by regional innovation capability, naturally provide strong internal support for the enhancement of regional soft power.

Fifthly, create a common development of regional cooperation in culture. Technological innovation activities is a very complex social and economic activities rely solely on the power of the individual technological innovation activities, the probability of success will be greatly reduced. Learn from the experience of the U.S. Silicon Valley high-tech enterprises in the continuous development of the culture of cooperation, and Silicon Valley innovation capabilities continue to highlight the important source. Culture of cooperation penetrated into every corner of the region, the formation taken to the atmosphere of the exchange of knowledge, knowledge sharing, and the formation of a tradition. Informal exchanges are very active, very common, cafes, clubs, gym and exhibition and so become an important place of exchange. It is because of the special atmosphere of cooperation and exchange in Silicon Valley, the information can be passed quickly in the region, spark of thought continue to get excited for continuous innovation to provide a very appropriate regional atmosphere. At present, the government of each province in China has a full understanding on research cooperation in regional technological innovation and scientific guidance at a policy level. If the cooperation between enterprises appropriate to be guided, so that the complementary strengths between the enterprises, I believe we can improve the efficiency of regional technological innovation, and every one participation and cooperation of enterprises can share the benefits of cooperation.

\section{REFERENCES}

[1] Cheng Tianquan, Improve the country's soft power: a major practical issue, Teaching and Research, 20082 5-8.

[2] Men Honghua, Assessment of China's soft power, international observation, 2007 2:15-26.

[3] Chen Zhengliang, Enhance the regional development of the theory of "soft power", the socialist Research 2005, 2:105-107.

[4] Chen Yiyuan, Culture of innovation: innovation, cultural driving force, Fujian Forum - Humanities and Social Science, 2007, 3:131-134.

[5] Xu Ziqing, Fujian's technological innovation and cultural basis in reality and its construction, Fujian Administration Institute, Fujian Economic Management Institute, 2008 a:49-53. 